\title{
MATÉRIA SECA E PRODUÇÃO DE GRÃOS DE Crotalaria juncea L. SUBMETIDA À PODA E ADUBAÇÃO FOSFATADA
}

\author{
Márcio Carreira Dourado; Tiago Roque Benetoli da Silva*; Antonio César Bolonhezi ${ }^{3}$ \\ ${ }^{1}$ Pós-Graduando do Depto. de Biologia FE/UNESP - Campus de Ilha Solteira. \\ ${ }^{2}$ Pós-Graduando do Depto. de Fitotecnia, Economia e Sociologia Rural FE/UNESP - Campus de Ilha Solteira. \\ ${ }^{3}$ Depto. de Fitotecnia, Economia e Sociologia Rural - FE/UNESP - Campus de Ilha Solteira, C.P. 31 - \\ CEP: 15385-000 - Ilha Solteira, SP. \\ *Autor correspondente <tiago.rbs@bol.com.br>
}

RESUMO: O estudo dos adubos verdes tem demonstrado um grande potencial na recuperação da produtividade do solo, e dentre as diversas leguminosas usadas como adubo verde, a Crotalária mostra-se muito eficiente como produtora de massa vegetal e como fixadora de nitrogênio. Este experimento foi realizado em um LATOSSOLO VERMELHO Distrófico (LVd), em Selvíria, MS, com o objetivo de avaliar os efeitos da adubação fosfatada e da poda em Crotalaria juncea L. na altura de $100 \mathrm{~cm}$, na produtividade de matéria seca e sementes. $O$ delineamento utilizado foi em blocos casualizados, em esquema fatorial $5 \times 2$ com quatro repetições. As cinco doses de $\mathrm{P}_{2} \mathrm{O}_{5}$ foram $0,60,120,180$ e $240 \mathrm{~kg} \mathrm{ha}^{-1}$. A poda foi realizada aos 60 dias após a emergência de plântulas. Avaliaram-se quinzenalmente a altura de plantas, a cobertura vegetal, a quantidade de matéria verde e seca das plantas, o diâmetro do caule das plantas, o número de ramos de 10 plantas. A análise da qualidade fisiológica das sementes foi realizada: teste de germinação, envelhecimento acelerado, pureza física, massa de 1000 sementes. Com a poda e a adubação fosfatada, não foi alterada a produção de matéria seca nem a de grãos de Crotalaria juncea L., mas apenas a qualidade fisiológica das sementes.

Palavras-chave: Crotalaria juncea, poda, sementes, adubação fosfatada

\section{DRY MATTER AND SEED PRODUCTION OF Crotalaria juncea L. SUBMITTED TO PRUNING AND PHOSPHATE FERTILIZATION}

\begin{abstract}
Green manure studies have shown a great potential for soil recuperation, the Crotalaria being a very efficient crop in producing residues and fixing nitrogen. This experiment was carried out on a Typic Hapludox, in Selvíria, MS, Brazil, with the objective of evaluating the effects of phosphate fertilization in relation to the pruning of Crotalaria juncea L., at the height of $100 \mathrm{~cm}$, in order to obtain an increase of the production of dry matter and seeds. The used design consisted of randomized blocks, in a fatorial outline $5 \times 2$, with four replicates. The five $\mathrm{P}_{2} \mathrm{O}_{5}$ levels were $0,60,120,180$ and $240 \mathrm{~kg} \mathrm{ha}^{-1}$. The pruning was performed 60 days after plants emerged. Forthnightly the height of plants, vegetative covering, green and dry matter weight plant quantity, diameter of the stem and the number of branches of 10 plants were evaluated. The analysis of the physiologic quality of the seeds was performed through a germination test, accelerated aging, physical purity, and weight of 1000 seeds. With pruning and phosphate fertilization, do not were modify and the dry matter and yield of Crotalaria juncea L. were not altered, but only the seed physiologic quality.

Key words: Crotalaria juncea, prunes, seeds, phosphate fertilization
\end{abstract}

\section{INTRODUÇÃO}

O cultivo de plantas adaptadas às diferentes regiões agroecológicas e promovendo a melhoria das propriedades dos solos agrícolas constitui numa prática milenar, cujo uso decresceu com o advento da adubação química e, nos últimos 10 anos, vem despertando novamente interesse (Tedesco, 1983). Embora se considere como adubação verde a incorporação ao solo de fitomassa de espécies vegetais distintas, as leguminosas são as mais difundidas para essa finalidade, por apresentarem um sistema radicular, em geral, profundo e ramificado, com capacidade de fixar o nitrogênio atmosférico, mediante simbiose com a bactéria do gênero Rhizobium. Essas características possibilitam às leguminosas a extração de elementos menos solúveis e a mobilização de nutrientes das camadas mais profundas do solo, tornando-os disponíveis as culturas econômicas após sua decomposição (Miyasaka, 1983).

A prática de adubação verde, embora apresente várias vantagens é, pouco utilizada pelos agricultores, principalmente durante o verão, pois para eles o cultivo de uma espécie de adubo verde não propicia retorno econômico imediato, ou seja, ocupa o espaço de outra cultura de renda. Isto ocorre em função do desconhecimento dos efeitos benéficos das plantas de cobertura nos sistemas de produção. Por outro lado, Skora Neto (1993) sugere que é desejável que a adubação verde seja considerada uma prática economicamente rentável.

Em estudos de Wildner (1992), em Santa Catarina, destacou-se a utilização de adubos verdes 
como cobertura do solo, possibilitando, além do controle da erosão, a diminuição da incidência de plantas daninhas, a redução das perdas de nutrientes, a atenuação das flutuações da temperatura do solo, contribuindo para a recuperação de áreas degradadas pelo mau uso do solo. Portanto, manter a cobertura pelo maior tempo possível é fundamental no manejo racional do solo.

$\mathrm{O}$ estudo dos adubos verdes tem demonstrado um grande potencial na recuperação da produtividade do solo. Um dos principais desafios está em se estabelecer um esquema de uso compatível das diferentes espécies com os sistemas de produção específicos de cada região, se possível nos limites de cada propriedade, levando-se em consideração os aspectos ligados ao clima, solo, infraestrutura da propriedade e condições sócio-econômicas do agricultor (Calegari, 1992). A utilização dessas plantas pode visar, além da conservação e/ou melhoria da fertilidade do solo, a própria produção de sementes como fonte de renda (Bulisani, 1992).

Dentre as diversas leguminosas usadas como adubo verde, a Crotalária é muito eficiente como produtora de massa vegetal e como fixadora de nitrogênio, (Salgado, 1982). Wutke (1993) diz que a Crotalaria juncea pode fixar 150 a $165 \mathrm{~kg} \mathrm{ha}^{-1} \mathrm{ano}^{-1}$ de nitrogênio no solo, podendo chegar a $450 \mathrm{~kg} \mathrm{ha}^{-1} \mathrm{ano}^{-1}$ em certas ocasiões, produzindo 10 a 15 toneladas de matéria seca correspondendo a 41 e $217 \mathrm{~kg} \mathrm{ha}^{-1}$ de $\mathrm{P}_{2} \mathrm{O}_{5}$ e $\mathrm{K}_{2} \mathrm{O}$ respectivamente. Aos 130 dias de idade pode apresentar raízes na profundidade de até $4,5 \mathrm{~m}$, sendo que $79 \%$ de seu peso se encontram nos primeiros 30 $\mathrm{cm}$. Esse mesmo autor ressalta que nem sempre 0 rendimento de fitomassa está associado ao aumento de produções das culturas subseqüentes. Há evidências de benefícios das excreções radiculares na sucessão Crotalária - cana-de-açúcar, e ainda, de efeitos alelopáticos sobre a tiririca.

Abboud \& Duque (1995), estudando a caracterização de leguminosas com potencial para adubação verde no período da seca, demonstraram que caso os agricultores queiram cortar o adubo verde no período da floração como é comumente recomendado, é possível que se façam dois cortes antes do período da safra aumentando-se a produção de material orgânico produzido.

Como a crotalária é uma planta usada para prática da adubação verde, não é adotada pelo agricultor brasileiro que visa a implantação culturas rentáveis. Portanto, como opção de renda extra, pode-se cultivar a crotalária para fins de produção de sementes, associando-se ainda à adubação fosfatada e à prática de poda, para aumento dessa produção de sementes.

Entretanto, os trabalhos sobre a influência da adubação fosfatada associada à poda na Crotalaria juncea L. são muito escassos na literatura. Lovadini et al. (1970) desenvolveram trabalhos no Estado de São Paulo a respeito da época de semeadura e da poda na produção de massa verde e sementes de Crotalaria juncea L., verificando que a semeadura entre outubro e dezembro resulta em melhor produtividade de sementes e massa verde, se comparada com a semeadura tardia. Quando a poda é executada em fevereiro é favorecida apenas a produção de massa verde e não a de sementes. Salgado et al. (1982) estudaram o efeito da adubação (NPK) na cultura da crotalária e concluíram que, para o aumento da produção de sementes e massa verde é essencialmente necessária a adubação fosfatada, na maioria dos solos do Estado de São Paulo, bem como, uma adubação completa (NPK) em solos pouco férteis. Enfatizaram também a necessidade de desenvolver novos experimentos para esclarecimento dos efeitos da adubação fosfatada associada à técnica de poda sobre a produção de matéria seca incorporável ao solo e de sementes para comercialização.

Dourado (1998) relatou, em seu experimento, um aumento significativo da produção de sementes de crotalária semeada em dezembro, e podada a uma altura de $100 \mathrm{~cm}$, quando comparado a outras alturas de poda, e ao tratamento sem poda das plantas.

Dourado \& Almeida (1998) em um experimento realizado em Selvíria, MS, relacionando alturas de poda e população de plantas de crotalária júncea, concluíram que a prática da poda tanto a 80 quanto a $100 \mathrm{~cm}$ de altura, não prejudica a produção de matéria seca total da planta, quando comparado com o tratamento sem poda.

Diante do exposto, evidencia-se a importância do uso da Crotalaria juncea L. como adubo verde, tendo o presente trabalho o objetivo de avaliar os efeitos da adubação fosfatada em conjunto com a técnica de poda em Crotalaria juncea L. visando aumento na produção de sementes e matéria seca.

\section{MATERIAL E MÉTODOS}

O presente ensaio foi instalado em área experimental pertencente à Faculdade de Engenharia de Ilha Solteira - UNESP, localizada no município de Selvíria - MS, apresentando coordenadas geográficas $51^{\circ} 22$ ' de longitude oeste de Greenwich e $20^{\circ} 22^{\prime}$ de latitude sul, com altitude de 335 metros, em um LATOSSOLO VERMELHO Distrófico típico argiloso, A moderado, hipodistrófico, álico, caulinítico, férrico, compactado, muito profundo, moderadamente ácido $(\mathrm{LVd})^{1}$.

As parcelas foram constituídas por 12 linhas no espaçamento de $0,5 \mathrm{~m}$, com 7 metros de comprimento, utilizando-se como área útil as dez linhas centrais, desconsiderando-se $0,5 \mathrm{~m}$ em cada extremidade da parcela. $O$ delineamento experimental utilizado foi em blocos ao acaso, com dez tratamentos distribuídos em esquema fatorial $2 \times 5$, com quatro repetições. Os tratamentos foram os seguintes: com poda (CP) e sem poda (SP), e as doses de $\mathrm{P}_{2} \mathrm{O}_{5}$ foram 0,60, 120, 180 e $240 \mathrm{~kg} \mathrm{ha}^{-1}$.

Foi utilizado o programa SANEST, sistema de Análise de Variância por microcomputadores (Zonta \& Machado, 1984) e as médias foram comparadas pelo teste de Tukey a $5 \%$ e regressão polinomial. 
A Crotalaria juncea L. foi semeada manualmente, em área preparada pelo sistema convencional (1 aração e 2 gradagens), para obtenção de 20 plantas viáveis por metro.

Para a adubação potássica foram utilizados 60 $\mathrm{kg} \mathrm{ha}^{-1}$ de $\mathrm{K}_{2} \mathrm{O}$ no sulco de semeadura, conforme resultados da análise química do solo e recomendação de Salgado (1996). A semeadura foi realizada no dia 7 de dezembro de 1998.

A poda foi realizada manualmente, com tesouras de poda, aos 60 dias após a emergência das plântulas, de acordo com a altura estabelecida de um metro por Dourado (1998), para obtenção de aumento na produção de sementes. Durante o desenvolvimento da cultura foram realizadas irrigações e controle de plantas infestantes, sempre que necessário.

No presente ensaio foram realizadas as seguintes avaliações:

Cobertura vegetal: foi realizada aos 30,45 e 60 dias após a emergência das plântulas, com a utilização do método do Ponto Quadrado, em dois pontos por parcela (Spedding \& Large, 1957). Este método consiste em colocar um quadrado de ferro com 1 metro de lado e quadriculado de $10 \mathrm{~cm}$ em $10 \mathrm{~cm}$ sobre a superfície das plantas sem tocá-las e contar os pontos coincidentes de cada interseção com qualquer parte vegetal. $O$ resultado é expresso em porcentagem de área coberta.

Quantidade de matéria verde e seca das plantas: determinada em plantas coletadas em $1 \mathrm{~m}^{2}$ na área útil de cada parcela, aos 60 dias após a emergência de plântulas (na realização da poda), aos 15, 30 e 45 dias após a poda e no ato da colheita. O material verde foi pesado, sendo seco em estufa com ventilação forçada à temperatura média de $60-70^{\circ} \mathrm{C}$, até atingir peso constante.

Diâmetro do caule de plantas: medido com o auxílio de um paquímetro (em milímetro), a cerca de 15 $\mathrm{cm}$ da superfície do solo, em 10 plantas por parcela, aos 60 dias após a emergência de plântulas (na realização da poda), aos 15, 30 e 45 dias após a poda, e no ato da colheita.

Altura de plantas: determinada em 10 plantas por parcela, medindo-se com uma régua de madeira desde a superfície do solo até a gema do ramo mais alto da planta, aos 60 dias após a emergência de plântulas (na realização da poda), aos 15, 30 e 45 dias após a poda, e no ato da colheita.

Número de ramos por planta: realizada a contagem do número de ramos em 10 plantas/parcela, aos 15, 30 e 45 dias após a poda.

Rendimento de grãos: determinado em área útil de $5 \mathrm{~m}^{2}$ por parcela, quando cerca de $70 \%$ das vagens estavam secas. Os dados foram convertidos em $\mathrm{kg} \mathrm{ha}^{-1}$.

A qualidade das sementes foi avaliada quanto à pureza física, massa de mil sementes e nos testes de germinação e de envelhecimento acelerado, de acordo com as Regras para Análises de Sementes (Brasil, 1992).

\section{RESULTADOS E DISCUSSÕES}

$\mathrm{Na}$ TABELA 1 estão relacionados os teores de nutrientes encontrados na área experimental.

Os resultados referentes à cobertura vegetal do solo e altura de plantas, aos 30 e 45 dias após a emergência das plantas, estão apresentados na TABELA 2. Não se observou efeito significativo do fator doses de fósforo em nenhum desses parâmetros avaliados, independentemente da época de avaliação.

Os resultados referentes ao diâmetro de caule, altura de plantas, quantidade da matéria verde e seca total, obtidos aos 60 dias após a emergência das plantas, ou seja, no ato da poda, estão apresentados na TABELA 3. Não houve efeito significativo do fator doses nas avaliações realizadas.

Os resultados referentes ao número de ramos, diâmetro de caule, altura de plantas, quantidade da matéria verde e a quantidade da matéria seca total, aos 15 dias após a poda, estão apresentados na TABELA 4. Houve efeito significativo para o diâmetro de plantas sendo a maior média $(8,47 \mathrm{~mm})$ pertencente às plantas não podadas. A altura de plantas significativamente maior $(2,74 \mathrm{~m})$ foi observada nas plantas não podadas, facilmente explicado pelo fato dessas plantas não serem rebaixadas pelo ato da poda. Conseqüentemente, a quantidade da matéria verde dessas plantas foi significativamente maior $\left(3,132 \mathrm{~kg} \mathrm{~m}^{-2}\right)$. Também foi significativamente maior a quantidade da matéria seca total $\left(8841 \mathrm{~kg} \mathrm{ha}^{-1}\right)$ obtida nas plantas não podadas, discordando de Dourado \& Almeida (1998). Esses autores afirmaram ser a prática da poda, tanto a $80 \mathrm{~cm}$ quanto a $100 \mathrm{~cm}$ de altura não prejudicial à produção de matéria seca total da planta, quando comparada ao tratamento sem poda.

Houve efeito significativo na quantidade de matéria seca total para as diferentes doses de fósforo. Os dados de doses de $\mathrm{P}_{2} \mathrm{O}_{5}$ se ajustaram a uma função $Y=5928,050+4,8266 x$.

Os resultados referentes ao diâmetro de caule, altura de plantas, quantidade da matéria verde e a quantidade da matéria seca total aos 30 dias após a poda, estão apresentados na TABELA 5. Não houve efeito significativo para o número de ramos, entretanto houve efeito significativo para o diâmetro de plantas sendo a maior média $(9,49 \mathrm{~mm})$ pertencente às plantas não podadas. A altura de plantas foi significativamente maior $(2,80 \mathrm{~m})$ nas plantas não podadas. Observou-se efeito significativo na altura da planta para as diferentes doses de fósforo. Os dados de doses de $\mathrm{P}_{2} \mathrm{O}_{5}$ se ajustaram a uma função $Y=2,3778+0,00168 x-$ $0,000009 x^{2}$. A quantidade da matéria verde de plantas significativamente maior $\left(3,293 \mathrm{~kg} \mathrm{~m}^{-2}\right)$ foi obtida pelas plantas não podadas. Foi significativamente maior o peso da matéria seca total $\left(9741,7 \mathrm{~kg} \mathrm{ha}^{-1}\right)$ obtidos pelas plantas não podadas. 
Os resultados referentes ao diâmetro de caule, altura de plantas, quantidade da matéria verde e a quantidade da matéria seca total aos 45 dias após a poda, estão apresentados na TABELA 6 . Não houve efeito significativo para o número de ramos nem para 0 diâmetro de plantas. A altura de plantas significativamente maior $(2,90 \mathrm{~m})$. Observou-se efeito significativo na altura de plantas para a interação poda $x$ doses. Os dados da interação se ajustaram a uma função $Y=2,73350+0,00392 x-0,0000139 x^{2}$. Foi significativamente maior a quantidade da matéria seca total (11304 $\mathrm{kg} \mathrm{ha}^{-1}$ ) obtida pelas plantas não podadas.

Os resultados referentes ao diâmetro de caule, altura de plantas, quantidade da matéria verde e a quantidade da matéria seca total no ato da colheita, estão apresentados na TABELA 7. Não houve efeito significativo para o número de ramos, porém, houve efeito significativo para o diâmetro de plantas, onde a maior média $(10,30 \mathrm{~mm})$ foi obtida pelas plantas que não receberam a poda. A altura de plantas foi significativamente maior $(2,99 \mathrm{~m})$ nas plantas não podadas. Não houve efeito significativo para a quantidade de matéria verde de plantas. Houve efeito significativo para a interação poda $x$ doses. Os dados da interação de doses dentro de plantas podadas se ajustaram a uma função $Y=458,7385-0,010470 x-$ $0,006093 x^{2}$, enquanto que os dados da interação doses dentro de plantas não podadas se ajustaram a uma função $Y=497,8328-2,86084 x-0,005672 x^{2}$.

Houve efeito significativo da poda para a quantidade da matéria seca obtida na colheita (TABELA 8). A maior média (12418 $\mathrm{kg} \mathrm{ha}^{-1}$ ) foi observada nas plantas não podadas, concordando com a faixa de variação de produção de matéria seca da Crotalaria juncea L., entre 10 a $15.000 \mathrm{~kg} \mathrm{ha}^{-1}$, mencionada por Wutke (1993). Entretanto, esses resultados discordam de Dourado \& Almeida (1998) que afirmaram ser a prática da poda não prejudicial à produção de matéria seca total da planta, quando comparada ao tratamento sem poda.
TABELA 1 - Teores de nutrientes em amostra de solo do tipo LATOSSOLO VERMELHO Distrófico (LVd). Selvíria, MS, 1998.

\begin{tabular}{|c|c|c|c|c|c|c|c|}
\hline$P$ resina & M.O. & $\mathrm{pH} \mathrm{CaCl}{ }_{2}$ & $\mathrm{~K}$ & $\mathrm{Ca}$ & $\mathrm{Mg}$ & $\mathrm{H}+\mathrm{Al} \quad \mathrm{Al}$ & V \\
\hline $\mathrm{mg} \mathrm{dm}^{-3}$ & $\mathrm{~g} \mathrm{dm}^{-3}$ & & --- & $---\mathrm{mr}$ & $\mathrm{mol}_{\mathrm{C}} \mathrm{c}$ & $\mathrm{Im}^{-3}$ & $\%$ \\
\hline 16 & 26,0 & 4,8 & 0,8 & 20,0 & 9,0 & 34,0 & 46 \\
\hline
\end{tabular}

TABELA 2 - Cobertura vegetal do solo e altura de plantas de crotalária júncea, aos 30 e 45 dias após sua emergência, sob diferentes doses de fósforo. Selvíria, MS, 1999.

\begin{tabular}{|c|c|c|c|c|}
\hline \multirow{2}{*}{$\begin{array}{l}\text { Doses de } \\
\text { fósforo }\end{array}$} & \multicolumn{2}{|c|}{$\begin{array}{c}\text { Cobertura vegetal do } \\
\text { solo }\end{array}$} & \multicolumn{2}{|c|}{ Altura de plantas } \\
\hline & $30 \mathrm{DAE}^{1}$ & $45 \mathrm{DAE}$ & $30 \mathrm{DAE}$ & $45 \mathrm{DAE}$ \\
\hline $\mathrm{kg} \mathrm{P}_{2} \mathrm{O}_{5} \mathrm{ha}^{-1}$ & \multicolumn{2}{|c|}{---_- } & \multicolumn{2}{|c|}{------- m ------ } \\
\hline 0 & 83,6 & 89,5 & 1,45 & 1,78 \\
\hline 60 & 84,3 & 90,1 & 1,46 & 1,76 \\
\hline 120 & 87,0 & 91,1 & 1,49 & 1,77 \\
\hline 180 & 88,1 & 91,0 & 1,54 & 1,80 \\
\hline 240 & 87,1 & 88,0 & 1,45 & 1,79 \\
\hline CV \% & 6,5 & 4,4 & 8,8 & 4,0 \\
\hline
\end{tabular}

'DAE: dias após a emergência de plântulas

TABELA 3 - Avaliação realizada no ato da poda da Crotalaria juncea L. aos 60 dias após a emergência, em função de diferentes doses de $\mathrm{P}_{2} \mathrm{O}_{5}$. Selvíria, MS, 1999.

\begin{tabular}{ccccc}
\hline $\begin{array}{c}\text { Doses de } \\
\text { fósforo }\end{array}$ & $\begin{array}{c}\text { Diâmetro de } \\
\text { caule }\end{array}$ & $\begin{array}{c}\text { Altura de } \\
\text { plantas }\end{array}$ & $\begin{array}{c}\text { Quantidade Quantidade } \\
\text { da matéria } \\
\text { verde }\end{array}$ & $\begin{array}{c}\text { da matéria } \\
\text { seca to tal }\end{array}$ \\
\hline $\mathrm{Kg} \mathrm{P}_{2} \mathrm{O}_{5} \mathrm{ha}^{-1}$ & $\mathrm{~mm}$ & $\mathrm{~m}$ & $\mathrm{~kg} \mathrm{~m}^{-2}$ & $\mathrm{~kg} \mathrm{ha}^{-1}$ \\
0 & 7,01 & 2,09 & 2,51 & 3409 \\
60 & 8,12 & 2,07 & 2,40 & 3696 \\
120 & 7,56 & 2,11 & 2,59 & 3509 \\
180 & 8,15 & 2,13 & 2,65 & 4266 \\
240 & 7,87 & 2,13 & 2,64 & 4058 \\
\hline CV \% & 8,5 & 3,2 & 13,8 & 16 \\
\hline
\end{tabular}

TABELA 4 - Avaliação realizada aos 15 dias após a poda deplantas da Crotalaria juncea L. em função de diferentes doses de $\mathrm{P}_{2} \mathrm{O}_{5}$ associadas à poda. Selvíria,MS,1999.

\begin{tabular}{|c|c|c|c|c|c|}
\hline $\begin{array}{c}\text { Causas de } \\
\text { variação }\end{array}$ & $\begin{array}{c}\text { № de ramos por } \\
10 \text { plantas }\end{array}$ & $\begin{array}{l}\text { Diâmetro de } \\
\text { caule }\end{array}$ & Altura de plantas & Matéria verde & $\begin{array}{c}\text { Matéria seca } \\
\text { total }\end{array}$ \\
\hline & & $\mathrm{mm}$ & $\mathrm{m}$ & $\mathrm{kg} \mathrm{m}^{-2}$ & $\mathrm{~kg} \mathrm{ha}^{-1}$ \\
\hline Com poda & 107 & $7,81 \mathrm{~b}$ & $1,48 \mathrm{~b}$ & $1,589 b$ & $4172 b$ \\
\hline Sem poda & 71 & $8,47 \mathrm{a}$ & $2,74 \mathrm{a}$ & $3,132 a$ & 8841 a \\
\hline \multicolumn{6}{|l|}{ Dose de fósforo } \\
\hline \multicolumn{6}{|l|}{$\mathrm{kg} \mathrm{P}_{2} \mathrm{O}_{5} \mathrm{ha}^{-1}$} \\
\hline 0 & 101 & 7,91 & 2,10 & 2,235 & 6038 \\
\hline 60 & 102 & 8,40 & 2,12 & 2,418 & 6000 \\
\hline 120 & 98 & 8,06 & 2,09 & 2,393 & 6712 \\
\hline 180 & 108 & 8,00 & 2,10 & 2,346 & 6599 \\
\hline 240 & 109 & 8,33 & 2,13 & 2,411 & 7185 \\
\hline CV\% & 15,1 & 10,9 & 3,8 & 13,7 & 9,0 \\
\hline
\end{tabular}

Médias seguidas de mesma letra não diferem pelo teste de Tukey a $5 \%$.

Scientia Agricola, v.58, n.2, p.287-293, abr./jun. 2001 
TABELA 5 - Avaliação realizada aos 30 dias após a poda de plantas da Crotalaria juncea L. em função de diferentes doses de $\mathrm{P}_{2} \mathrm{O}_{5}$ associadas à poda. Selvíria, MS, 1999.

\begin{tabular}{|c|c|c|c|c|c|}
\hline $\begin{array}{c}\text { Causas de } \\
\text { variação }\end{array}$ & $\begin{array}{l}\text { № de ramos por } \\
10 \text { plantas }\end{array}$ & Diâmetro de caule & Altura de plantas & Matéria verde & $\begin{array}{l}\text { Matéria seca } \\
\text { total }\end{array}$ \\
\hline & & $\mathrm{mm}$ & $\mathrm{m}$ & $\mathrm{kg} \mathrm{m}^{-2}$ & $\mathrm{~kg} \mathrm{ha}^{-1}$ \\
\hline Com poda & 103 & $8,43 \mathrm{~b}$ & $1,95 b$ & $2,461 \mathrm{~b}$ & $5494 \mathrm{~b}$ \\
\hline Sem poda & 85 & $9,49 a$ & $2,80 \mathrm{a}$ & $3,293 \mathrm{a}$ & $9742 \mathrm{a}$ \\
\hline \multicolumn{6}{|l|}{ Dose de fósforo } \\
\hline \multicolumn{6}{|l|}{$\mathrm{kg} \mathrm{P}_{2} \mathrm{O}_{5} \mathrm{ha}^{-1}$} \\
\hline 0 & 82 & 9,01 & 2,44 & 2,726 & 8190 \\
\hline 60 & 88 & 8,98 & 2,41 & 2,801 & 7366 \\
\hline 120 & 102 & 8,96 & 2,37 & 2,877 & 4862 \\
\hline 180 & 101 & 9,33 & 2,34 & 2,952 & 7822 \\
\hline 240 & 95 & 8,69 & 2,31 & 3,028 & 7350 \\
\hline CV\% & 25,4 & 10,5 & 6,5 & 16,2 & 23,9 \\
\hline
\end{tabular}

Médias seguidas de mesma letra não diferem pelo teste de Tukey a 5\%.

TABELA 6 - Avaliação realizada aos 45 dias após a poda de plantas da Crotalaria juncea L. em função de diferentes doses de $\mathrm{P}_{2} \mathrm{O}_{5}$ associadas à poda. Selvíria, MS, 1999.

\begin{tabular}{|c|c|c|c|c|c|}
\hline $\begin{array}{l}\text { Causas de } \\
\text { variação }\end{array}$ & $\begin{array}{l}\text { № de ramos } \\
\text { por } 10 \text { plantas }\end{array}$ & Diâmetro de caule & Altura de plantas & Matéria verde & Matéria seca total \\
\hline & & $\mathrm{mm}$ & $\mathrm{m}$ & $\mathrm{kg} \mathrm{m}^{-2}$ & $\mathrm{~kg} \mathrm{ha}^{-1}$ \\
\hline Com poda & 126 & 9,26 & $2,22 b$ & 3,130 & $7658 b$ \\
\hline Sem poda & 115 & 9,96 & $2,90 \mathrm{a}$ & 3,676 & $11304 \mathrm{a}$ \\
\hline \multicolumn{6}{|l|}{ Dose de fósforo } \\
\hline \multicolumn{6}{|l|}{$\mathrm{kg} \mathrm{P}_{2} \mathrm{O}_{5} \mathrm{ha}^{-1}$} \\
\hline 0 & 122 & 9,84 & 2,50 & 3,283 & 9501 \\
\hline 60 & 125 & 8,96 & 2,53 & 3,291 & 9142 \\
\hline 120 & 123 & 9,46 & 2,56 & 3,311 & 9277 \\
\hline 180 & 122 & 9,84 & 2,59 & 3,587 & 8952 \\
\hline 240 & 110 & 9,93 & 2,63 & 3,543 & 10533 \\
\hline CV \% & 14,4 & 12,7 & 5,7 & 12,2 & 17,9 \\
\hline
\end{tabular}

Médias seguidas de mesma letra não diferem pelo teste de Tukey a 5\%.

TABELA 7 - Avaliação realizada na colheita da Crotalaria juncea L. em função de diferentes doses de $\mathrm{P}_{2} \mathrm{O}_{5}$ associadas à poda. Selvíria, MS, 1999.

\begin{tabular}{|c|c|c|c|c|c|}
\hline $\begin{array}{l}\text { Causas de } \\
\text { variação }\end{array}$ & $\begin{array}{c}\text { № de ramos por } 10 \\
\text { plantas }\end{array}$ & Diâmetro de caule & Altura de plantas & Matéria verde & $\begin{array}{c}\text { Matéria seca } \\
\text { total }\end{array}$ \\
\hline & & $\mathrm{mm}$ & $\mathrm{m}$ & $\mathrm{kg} \mathrm{m}^{-2}$ & $\mathrm{~kg} \mathrm{ha}^{-1}$ \\
\hline Com poda & 126 & $9,07 \mathrm{~b}$ & $2,31 \mathrm{~b}$ & 2,664 & 10329 \\
\hline Sem poda & 115 & $10,30 a$ & $2,99 a$ & 2,811 & 12418 \\
\hline \multicolumn{6}{|l|}{ Dose de fósforo } \\
\hline \multicolumn{6}{|l|}{$\mathrm{kg} \mathrm{P}_{2} \mathrm{O}_{5} \mathrm{ha}^{-1}$} \\
\hline 0 & 122 & 9,62 & 2,60 & 2,875 & 11365 \\
\hline 60 & 125 & 9,75 & 2,66 & 2,55 & 10918 \\
\hline 120 & 123 & 9,35 & 2,65 & 2,728 & 11409 \\
\hline 180 & 122 & 10,01 & 2,74 & 2,863 & 12113 \\
\hline 240 & 110 & 9,71 & 2,61 & 2,665 & 11062 \\
\hline CV\% & 14,4 & 10,7 & 5,7 & 14,3 & 11,3 \\
\hline
\end{tabular}

Médias seguidas de mesma letra não diferem pelo teste de Tukey a 5\%. 
TABELA 8 - Avaliação realizada na colheita de plantas da Crotalaria juncea L. em função de diferentes doses de $\mathrm{P}_{2} \mathrm{O}_{5}$ associadas à poda. Selvíria, MS, 1999.

\begin{tabular}{|c|c|c|c|c|}
\hline $\begin{array}{c}\text { Causas de } \\
\text { variação }\end{array}$ & M.V..$^{(1)}$ & M.S.T. ${ }^{(2)}$ & M.S. ${ }^{(3)}$ & $\begin{array}{l}\text { Produção } \\
\text { de grãos }\end{array}$ \\
\hline \multicolumn{5}{|c|}{ - } \\
\hline Com poda & & $10329 \mathrm{~b}$ & 12913 & 614 \\
\hline Sem poda & & $12418 \mathrm{a}$ & 15966 & 600 \\
\hline \multicolumn{5}{|l|}{$\begin{array}{l}\text { Dose de } \\
\text { fósforo }\end{array}$} \\
\hline \multicolumn{5}{|l|}{$\mathrm{kg} \mathrm{P}_{2} \mathrm{O}_{5} \mathrm{ha}^{-1}$} \\
\hline 0 & 3409 & 11365 & 12432 & 618 \\
\hline 60 & 3696 & 10919 & 11850 & 603 \\
\hline 120 & 3509 & 11409 & 12684 & 636 \\
\hline 180 & 4266 & 12113 & 13316 & 605 \\
\hline 240 & 4058 & 11061 & 12111 & 608 \\
\hline CV \% & 16,0 & 11,3 & 13,6 & 21,8 \\
\hline \multicolumn{5}{|c|}{$\begin{array}{l}\text { 'Matéria verde remanescente no solo após poda; } \\
{ }^{2} \text { Matéria seca total na colheita; } \\
{ }^{3} \text { Matéria seca total na colheita e remanescente no solo após poda. } \\
\text { Médias seguidas de mesma letra não diferem pelo teste de Tukey } \\
\text { a } 5 \% \text {. }\end{array}$} \\
\hline
\end{tabular}

Em relação à somatória da quantidade de matéria seca obtida na colheita e daquela remanescente no solo no ato da poda, não houve efeito significativo tanto para doses como para a poda, concordando com Salgado et al. (1984). Segundo esses autores, não há aumento significativo da produção de matéria seca, em função da adubação fosfatada, exceto em condições de solos com baixos teores deste elemento.

Não houve efeito significativo para a produção de grãos (TABELA 8). Esse resultado é oposto ao obtido por Dourado (1998), em que houve aumento significativo da produção de sementes, com poda a $100 \mathrm{~cm}$, quando comparado com plantas não podadas e com outras alturas de poda.

Os resultados referentes às características fisiológicas das sementes de Crotalaria juncea L., produzidas sob diferentes doses de fósforo e associadas à poda, a um metro de altura, estão apresentados na TABELA 9. Houve efeito significativo da poda na germinação de sementes, vigor, pureza física e massa de 1000 sementes. Nas plantas não podadas observaram-se as maiores médias para a germinação de sementes e naquelas podadas, produziram-se sementes com maior vigor, pureza física e massa de 1000 sementes. Nas doses de fósforo testadas verificou-se influência significativa na germinação, vigor e pureza física das sementes. As maiores médias de germinação e vigor foram obtidas com a dose de $240 \mathrm{~kg} \mathrm{ha}^{-1}$ de $\mathrm{P}_{2} \mathrm{O}_{5}$ e, para pureza física, com a dose de $180 \mathrm{~kg} \mathrm{ha}^{-1}$ de $\mathrm{P}_{2} \mathrm{O}_{5}$. Houve efeito significativo para a interação poda $\mathrm{x}$ doses de fósforo
TABELA 9 - Avaliação da qualidade fisiológica das sementes de Crotalaria juncea L. em função de diferentes doses de $\mathrm{P}_{2} \mathrm{O}_{5}$ aplicadas no sulco de semeadura, associadas à poda. Selvíria, MS, 1999.

\begin{tabular}{|c|c|c|c|c|}
\hline $\begin{array}{l}\text { Causas de } \\
\text { variação }\end{array}$ & Germinação & $\begin{array}{c}\text { Vigor } \\
\text { (Envelhecimento } \\
\text { Acelerado) }\end{array}$ & $\begin{array}{l}\text { Pureza } \\
\text { Física }\end{array}$ & $\begin{array}{c}\text { Massa de } \\
1000 \\
\text { sementes }\end{array}$ \\
\hline & \multicolumn{3}{|c|}{ 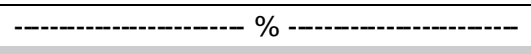 } & $g$ \\
\hline Com poda & $56,59 \mathrm{~b}$ & $81,28 \mathrm{a}$ & $61,35 \mathrm{a}$ & $50,42 \mathrm{a}$ \\
\hline Sem poda & $66,89 a$ & $70,72 b$ & $58,67 \mathrm{~b}$ & $40,76 \mathrm{~b}$ \\
\hline \multicolumn{5}{|l|}{$\begin{array}{l}\text { Dose de } \\
\text { fósforo }\end{array}$} \\
\hline \multicolumn{5}{|l|}{$\mathrm{kg} \mathrm{P}_{2} \mathrm{O}_{5} \mathrm{ha}^{-1}$} \\
\hline 0 & 63,58 e & 70,53 e & $59,99 \mathrm{c}$ & 50,26 a \\
\hline 60 & $65,77 d$ & $78,92 \mathrm{~b}$ & $61,74 \mathrm{~b}$ & $40,85 \mathrm{a}$ \\
\hline 120 & $71,25 \mathrm{c}$ & $72,85 d$ & $57,98 d$ & $50,15 a$ \\
\hline 180 & $74,54 \mathrm{~b}$ & $75,87 c$ & $68,47 \mathrm{a}$ & $40,97 \mathrm{a}$ \\
\hline 240 & $78,93 \mathrm{a}$ & $81,63 \mathrm{a}$ & 52,39 e & $50,24 a$ \\
\hline CV \% & 7,2 & 3,0 & 1,9 & 7,3 \\
\hline
\end{tabular}

Médias seguidas de mesma letra não diferem pelo teste deTukey a $5 \%$.

para pureza física das sementes, com ajuste dos dados a uma função quadrática $Y=7,6477+0,00972-$ $0,0000439 x^{2}$. Observou-se efeito de doses para pureza física, sendo a melhor dose testada a de $120 \mathrm{~kg} \mathrm{ha}^{-1}$ de $\mathrm{P}_{2} \mathrm{O}_{5}$, com ajuste a uma função quadrática $\mathrm{Y}=$ $7,69917+0,005616 x-0,0000275 x^{2}$. Houve efeito significativo para a interação poda $x$ doses de fósforo para massa de 1000 sementes. Observou-se efeito das doses de fósforo tanto nas plantas podadas como nas testemunhas, com ajustes respectivos a uma função linear $Y=4,456+0,002612 x$ e quadrática $Y=6,0775$ $-0,01446 x+0,000050 x$.

\section{CONCLUSÃO}

Com a poda e a adubação fosfatada, não foi alterada a produção de matéria seca nem a de grãos de Crotalaria juncea L., mas apenas a qualidade fisiológica das sementes.

\section{AGRADECIMENTOS}

Ao CNPq/PIBIC pela concessão de bolsa para realização desse trabalho.

\section{REFERÊNCIAS BILIOGRÁFICAS}

ABBOUD, A.C.S.; DUQUE, F.F. Caracterização de leguminosas com potencial para a adubação verde no período da seca. In: CONGRESSO BRASILEIRO DE CIÊNCIA DO SOLO, 24., Campinas, 1995. Resumos. Campinas: Sociedade Brasileira de Ciência do Solo, 1995. p.99-100.

BRASIL. Ministério da Agricultura. Regras para análise de sementes. Brasília: SNAD, DNPV, CLAV, 1992. 365p. 
BULISANI, E.A. Adubação verde nos estados de São Paulo, Paraná, Santa Catarina e Rio Grande do Sul. In: COSTA, M.B.B. (Coord.) Adubação verde no sul do Brasil. Rio de Janeiro: AS-PTA, 1992. p.57-195.

CALEGARI, A; MOUDARDO, A.; BULIZANI, E.A.; DA COSTA, M.B.B.; MIYASAKA, S.; AMADO, T.J.C. Aspectos gerais da adubação verde. In: COSTA, M.B.B.(Coord.). Adubação verde no sul do Brasil. Rio de Janeiro: AS-PTA, 1992. p.1-55.

DOURADO, M.C. Comportamento da Crotalaria juncea L. quando semeada em duas populações de plantas, submetidas a diferentes alturas de poda, visando a produção de sementes. In: CONGRESSO DE INICIAÇÃO CIENTÍFICA, 10. , Araraquara, 1998. Resumos. São Paulo: CNPq, 1998. p.336.

DOURADO, M.C.; ALMEIDA, C.R. Comportamento da Crotalaria juncea $\mathrm{L}$. quando associada a três diferentes alturas de poda e duas densidades de plantas. In: CONGRESSO DE INICIAÇÃO CIENTÍFICA, 10., Araraquara, 1998. Resumos. São Paulo: CNPq, 1998. p.335.

MIYASAKA, S. Adubação orgânica, adubação verde e rotação de culturas do Estado de São Paulo. Campinas: Fundação Cargill, 1983. 109p.

LOVADINI, L.A.C.; SALGADO, A.L.B.; MIYASAKA, S. Efeito da época de plantio e da poda e na produção de massa verde sementes de Crotalária juncea. Bragantia,v.29, p.2529,1970 .

SALGADO, A.L.B.; AZZINI, A.; FEITOSA, C.T; PETINELLI, A.; VEIGA, A.A. Efeito da adubação NPK na cultura da Crotalária. Bragantia, v.41, p.21-33, 1982.

SALGADO, A.L.B.; AZZINI, A.; FEITOSA, C.T; PETINELLI, A.; VEIGA, A.A. Adubação NPK e calagem na produção de massa verde e sementes de Cratalária. Bragantia, v.43, p.271-278, 1984.
SALGADO, A.L.B. Crotalária juncea. In: RAIJ, B. van; CANTARELA, H.; QUAGGIO, J.A.; FURLANI, A.M.C. Recomendações de adubação e calagem para o Estado de São Paulo. 2.ed. Campinas: IAC, 1996. p.113. (Boletim Técnico, 100).

SKORA NETO, F. Controle de plantas daninhas através de coberturas verdes consorciadas com milho. Pesquisa Agropecuária Brasileira, v.28, p.1165-1171, 1993.

SPEDDING, C.R.W.; LARGE, R. A point quadrat method for the description of pasture in terms of height and densiy. Journal of the British Grassland Society, v.12, p.229-234, 1957.

TEDESCO, M.J. Matéria orgânica e nitrogênio. Porto Alegre: UFRGS, 1983. p.87-123.

WUTKE, E.B. Adubação Verde, manejo da fitomassa e espécies utilizadas no Estado de São Paulo. In: WRITKE, E.B.; BULISANI, E.A.; MASCARENHAS, H.A.A. Curso de adubação verde no Instituto Agronômico. Campinas: Instituto Agronômico, 1993. p.17-29. (Documentos, 15).

WILDNER, L.P. Utilização de espécies de verão para adubação verde, cobertura e recuperação do solo em Santa Catarina. In: ENCONTRO NACIONAL DE ROTAÇÃO DE CULTURAS, 2., Campo Mourão, 1992. Anais. Campo Mourão: AEACM, 1992. p.144-160.

ZONTA, E.P.; MACHADO, A.A. Sistema de análise estatística para microcomputadores - SANEST. Pelotas: VFPel, 1984. (Disquete).

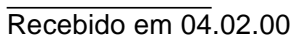

